\title{
Progress in Clinical Neurosciences: Treatment of Alzheimer's Disease and Other Dementias - Review and Comparison of the Cholinesterase Inhibitors
}

\author{
David B. Hogan, Christopher Patterson
}

\begin{abstract}
Background: Alzheimer's disease (AD) is the most common cause of dementia in older adults. Acceptance of the cholinergic hypothesis led to a search for medications which could enhance central cholinergic activity in this condition. There are now three cholinesterase inhibitors available for the treatment of AD in Canada. Objectives: To review the currently available cholinesterase inhibitors approved for the treatment of AD in Canada and to provide guidance on who and how to treat with these agents. Results: Donepezil, rivastigmine, and galantamine are approved for the treatment of AD in Canada. In clinical trails, patients with mild to moderate AD treated with these agents experienced modest improvements in cognition, function, behaviour, and/or global clinical state. The magnitude of benefits seen with each agent appeared to be similar. While to date, there is no convincing evidence that one is more efficacious or effective, they do differ in their pharmacokinetics, additional mechanisms of action, and side effect profiles. Therefore, the selection of agent will be based on considerations such as side effect profiles, ease of administration, personal familiarity/experience, and beliefs about the importance of the noted differences in their pharmacokinetics and additional mechanisms of action. Conclusion: We believe that these agents should be offered to all individuals with a mild to moderate dementia where Alzheimer's pathology is felt to be a contributing factor. We view all three available cholinesterase inhibitors as first-line drugs.
\end{abstract}

RÉSUMÉ: Traitement de la maladie d'Alzheimer- Revue et comparaison des inhibiteurs de la cholinestérase. Introduction: La maladie d'Alzheimer (MA) est la cause la plus fréquente de démence chez les personnes âgées. L'acceptation de l'hypothèse cholinergique a mené à la recherche de médicaments qui pourraient augmenter l'activité cholinergique centrale dans cette maladie. Il y a maintenant trois inhibiteurs de la cholinestérase qui sont disponibles au Canada pour le traitement de la maladie d'Alzheimer. Objectifs: Revoir les inhibiteurs de la cholinestérase qui sont actuellement disponibles et approuvés pour le traitement de la MAau Canada et fournir des conseils sur le type de patient qui doit être traité par ces agents et sur la façon dont ces patients doivent être traités. Résultats: Le donépézil, la rivastigmine et la galantamine sont approuvés pour le traitement de la MAau Canada. Chez des patients sélectionnés, atteints de MAde légère à modérée, le traitement au moyen de ces agents produit des améliorations modestes de la cognition, du niveau fonctionnel, du comportement et/ou de l'état clinique global. L'ampleur des bénéfices observés avec l'un ou l'autre de ces agents paraît similaire. À date, il n'y a pas d'évidence convainquante qu'un de ces agents soit plus efficace. Ils diffèrent quant à la pharmacocinétique, aux mécanismes d'action additionnels et au profil d'effets secondaires. Le choix d'un agent sera fondé sur des considérations telles que le profil d'effets secondaires, la facilité d'administration, la familiarité/l'expérience personnelle et les croyances sur l'importance de certaines différences dans la pharmacocinétique et les mécanismes d'action additionnels. Conclusion: Nous croyons que ces agents devraient être offerts à toutes les personnes ayant une démence légère à modérée, chez qui on croit que la MA est un facteur contributeur. Nous considérons les trois inhibiteurs de la cholinestérase présentement disponibles comme des médicaments de première ligne.

Can. J. Neurol. Sci. 2002; 29: 306-314

Alzheimer's disease (AD) is the most common type of dementia encountered in older patients. ${ }^{1,2}$ To date, the most successful pharmacological approach to the treatment of AD has been with cholinesterase inhibitors (ChEIs) which are felt to increase acetylcholine (ACh) levels in the central nervous system (CNS) by interfering with the hydrolysis of ACh by acetylcholinesterase (AChE) and/or butyrylcholinesterase (BuChE). In this paper we will review the ChEIs approved by the Therapeutics Products Program of Health Canada for the symptomatic treatment of $\mathrm{AD}$. We will compare these three agents (listed in order of approval - donepezil, rivastigmine, and galantamine) and give guidance as to who should be treated with what and how.

\section{CHOLINERGIC HYPOTHESIS}

Cholinergic neurons manufacture choline acetyltransferase which is transported down axons to projection targets where it catalyzes the synthesis of the neurotransmitter ACh. Acetylcholine is released into the synaptic cleft where it may

From the Department of Medicine, University of Calgary, Calgary, Alberta (DBH); and the Division of Geriatric Medicine, Department of Medicine, Faculty of Health Sciences, McMaster University, Hamilton, Ontario (CP) Canada. ReCEIVED March 12, 2001. ACCEPTED InFinALFORM July 9, 2002. Reprint requests to: David B. Hogan, Health Sciences Centre, 3330 Hospital Drive NW, Calgary, Alberta T2N 4N1 Canada. 
bind to a receptor. There are two classes of cholinergic receptors - muscarinic and nicotinic. Acetylcholine remains active until it is hydrolyzed to choline and acetate by cholinesterase. There are two cholinesterases in the CNS - AChE and BuChE. Acetylcholinesterase is found intraneuronally, in the synpatic cleft (in a soluble form) and in the synaptic membrane (in a membrane-bound form). ${ }^{3}$ By blocking the hydrolysis of ACh in the synaptic cleft, inhibitors of AChE can increase the amount of $\mathrm{ACh}$ available for cholinergic receptors. Butyrylcholinesterase is associated with glial cells. It comprises $10 \%$ of the total amount of cholinesterase activity in the normal adult brain., ${ }^{4,5}$ Butyrylcholinesterase is felt to be involved in the regulation of neurotransmission (cholinergic and noncholinergic) and might serve as a scavenger in the detoxification of certain chemicals. ${ }^{4,6}$ Both enzymes are found in neuritic plaques. ${ }^{4}$

Simply put, the cholinergic hypothesis holds that AD causes a cerebral cholinergic deficit that leads to the manifestations of the condition. ${ }^{7}$ This hypothesis is supported by a number of observations. Specific abnormalities of cholinergic neurons have been found in the brains of individuals suffering from AD. Postmortem studies have shown that patients dying with advanced $\mathrm{AD}$ have markedly reduced choline acetyltransferse brain activity. In the basal forebrain of those with $\mathrm{AD}$, there is severe loss of the neurons which provide the primary cholinergic input to the cortex. Pharmacological disruption of CNS cholinergic function can partially mimic the cognitive losses found in $\mathrm{AD}$. Cholinergic antagonists interfere with learning and cholinergic agonists facilitate learning. ${ }^{8}$

These findings led to a search for therapeutic agents which could correct the cholinergic deficit. The most effective means of correcting the cholinergic defect to date has been by preventing the breakdown of ACh by inhibiting AChE. The first AChE inhibitor marketed for the treatment of AD was tacrine, but its use was hampered by its short duration of action (requiring four times daily dosing) and liver toxicity. It was never approved for use in Canada. Since 1997, three ChEIs have been approved in Canada for the symptomatic treatment of $\mathrm{AD}$. In vitro and in vivo studies suggest that these agents might modify the course of AD. ${ }^{4,9}$ For example, a lesion of the nucleus basalis of Meynert leads to a rapid increase in the amount of amyloid precursor protein found in the rat brain. This can be reversed by ChEI therapy. ${ }^{9}$ Short-term in vitro treatment with a ChEI increases the release of nonaggregating fragments of amyloid precursor protein. A re-enforcing betaamyloid cycle that ChEIs can block has been proposed. ${ }^{9}$ Acetylcholinesterase accelerates both the formation and deposition of beta-amyloid. In turn, the synthesis of AChE is stimulated by the presence of beta-amyloid. Inhibiting $\mathrm{AChE}$ activity reduces beta-amyloid deposition which in turn would lead to less AChE being formed. While intriguing, the proposed disease-modifying properties of ChEIs have not been firmly established.

Paradoxically, now that there is evidence that enhancing central cholinergic activity partially corrects the observed cognitive deficits, recent research has led to a questioning of the primacy of a cholinergic deficit in early AD. For example, Davis et $\mathrm{al}^{10}$ found that cholinergic deficits only became apparent late in the course of $\mathrm{AD}$ - long after the disease was clinically evident. Likewise DeKosky et $\mathrm{al}^{11}$ found that choline acetyltransferase activity was only significantly reduced in end- stage AD. In fact, they found that there was elevated choline acetyltransferase activity (suggesting upregulation of the cholinergic system) in the frontal cortex and hippocampus with mild cognitive impairment which many feel is the initial symptomatic stage of $\mathrm{AD}$.

\section{Available ChOlinesterase inhibitors fOr Alzheimer's DISEASE}

The Cochrane Dementia and Cognitive Improvement Group has examined the clinical efficacy and safety of donepezil, rivastigmine, and galantamine for patients with AD. ${ }^{12-14}$ These systematic reviews of the evidence concluded that in clinical studies of patients with mild to moderate $\mathrm{AD}$, each ChEI produced modest improvements in cognition, function, behaviour and/or global clinical state. Doses at the higher end of the recommended ranges were generally associated with both greater benefits and more side effects. This underlies the typical approach with these agents to cautiously escalate the dosage to the highest tolerated level within the recommended therapeutic range. A statistically significant dose-response effect has been shown for rivastigmine. ${ }^{15}$ The magnitude of the effect on cognition (2-4 points on the ADAS-Cog, a 70-point scale) and the proportion showing an improvement on the global measure (20-27\%) after six months of therapy were similar for each agent. ${ }^{12-14,16}$ The authors of the reports did not comment on the practical or economic importance of these effects. A report from the Canadian Coordinating Office for Health Technology Assessment concluded that patients with AD treated with donepezil and rivastigmine had better cognitive performance than those receiving placebo (galantamine was not reviewed for this report). ${ }^{17}$ Not all treated patients respond to ChEIs. Unfortunately, ChEI responders cannot be reliably determined before starting therapy. Earlier AD studies of ChEIs were criticized for being of too short in duration. Fifty-two-week controlled trial data for donepezil have been reported ${ }^{18,19}$ and one to 4.9 years open-label study results are now available for each of the three ChEIs. ${ }^{20-22}$ More severely impaired AD patients have also been studied and have shown favourable outcomes. ${ }^{23,24}$ See Table 1 for a comparison of the three ChEIs. ${ }^{25-27}$

\section{UTILITY FOR NON-ALZHEIMER DEMENTIAS}

While only approved for the treatment of $\mathrm{AD}$, ChEIs have been evaluated in a number of non-AD dementias. The commonest types encountered are dementia with Lewy bodies (DLB), vascular dementia (VaD), and frontotemporal dementia. $^{28} \mathrm{~A}$ randomized controlled trial (RCT) compared rivastigmine to placebo in DLB. On the intention-to-treat analysis active therapy was superior to placebo $(p=0.01)$ on a computerized cognitive assessment which was one of the two primary efficacy measures. ${ }^{29}$ There was a trend $(p=0.088)$ for improvement on a neuropsychiatric measure which was the second primary outcome measure. Published case series support the use of donepezil in DLB. ${ }^{30,31}$

Galantamine, donepezil, and rivastigmine have all been studied in VaD. A RCTshowed greater efficacy with galantamine compared to placebo in subjects with either probable $\mathrm{VaD}$ or possible $\mathrm{AD}$ with radiological evidence of cerebrovascular disease. ${ }^{32}$ Statistically significant benefits were seen on 
Table 1: Comparison of donepezil, rivastigmine, and galantamine.

\begin{tabular}{|c|c|c|c|}
\hline & Donepezil & Rivastigmine & Galantamine \\
\hline Class & Piperidine & Carbamate & $\begin{array}{l}\text { Tertiary alkaloid and } \\
\text { phenanthrene derivative }\end{array}$ \\
\hline Mechanism & $\begin{array}{l}\text { Reversible } \\
\text { AChE inhibitor }\end{array}$ & $\begin{array}{l}\text { Pseudo-irreversible } \\
\text { AChE/BuChE inhibitor }\end{array}$ & $\begin{array}{l}\text { Reversible AChE inhibitor and } \\
\text { allosteric modulator of nicotinic receptors }\end{array}$ \\
\hline Pharmacokinetics & $\begin{array}{l}\text { Rapidly absorbed; } \\
\text { highly bound to plasma proteins; } \\
\text { liver metabolism } \\
\text { (P450 Isozymes 2D6 and 3A4) }\end{array}$ & $\begin{array}{l}\text { Rapidly absorbed; } \\
\text { food delays; hydrolyzed by } \\
\text { esterases; duration of } \\
\text { ChEI in the CNS is } 10 \text { hours }\end{array}$ & $\begin{array}{l}\text { Rapidly absorbed; } \\
\text { food delays; liver metabolism } \\
\text { (P450 Isoenzymes 2D6and 3A4) }\end{array}$ \\
\hline Half-Life & 70 hours & 1-2 hours & 5-7 hours \\
\hline Drug Interactiions & $\begin{array}{l}\text { Might interact with drugs } \\
\text { metabolized by } \mathrm{P} 450 \text { isoenzymes; } \\
\text { drugs which affect cholinergic system }\end{array}$ & $\begin{array}{l}\text { Drugs which affect } \\
\text { cholinergic system }\end{array}$ & $\begin{array}{l}\text { Might interact with drugs metabolized } \\
\text { by P450 isoenzymes; drugs which affect } \\
\text { cholinergic system }\end{array}$ \\
\hline Escalation & $\begin{array}{l}\text { To } 10 \mathrm{mg} \text { OD in } 4 \text { weeks } \\
\text { as tolerated }\end{array}$ & $\begin{array}{l}\text { To } 3.0 \mathrm{mg} \text { BID in } 4 \text { weeks, } \\
\text { with option to go to } 4.5 \mathrm{mg} \text { BID in } \\
4 \text { weeks, with option to go to } \\
6.0 \mathrm{mg} \text { BID in } 4 \text { weeks, as tolerated }\end{array}$ & $\begin{array}{l}\text { To } 8 \mathrm{mg} \text { BID in } 4 \text { weeks with } \\
\text { option to go to } 12 \mathrm{mg} \text { BID in } 4 \text { weeks, } \\
\text { as tolerated }\end{array}$ \\
\hline Maximum Dose & $10 \mathrm{mg}$ OD & $6.0 \mathrm{mg}$ BID & $12 \mathrm{mg}$ BID \\
\hline $\begin{array}{l}\text { Common Adverse } \\
\text { Effects }\end{array}$ & $\begin{array}{l}\text { Nausea, diarrhea, vomiting, } \\
\text { insomnia, muscle cramps, } \\
\text { anorexia }\end{array}$ & $\begin{array}{l}\text { Nausea, vomiting, diarrhea, } \\
\text { abdominal pain, anorexia, } \\
\text { weight loss }\end{array}$ & $\begin{array}{l}\text { Nausea, vomiting, dizziness, diarrhea } \\
\text { anorexia, weight loss }\end{array}$ \\
\hline
\end{tabular}

cognition, global functioning, activities of daily living and behavioural symptoms. The study was not adequately powered to detect treatment differences between the subgroups. There are less compelling published data supporting the use of both rivastigmine $^{33}$ and donepezil ${ }^{34}$ in $\mathrm{VaD}$. There are no published data indicating that the ChEIs are useful in frontotemporal dementia.

Cholinesterase inhibitors have been studied in a number of less common dementias. Both a case series ${ }^{35}$ and a $\mathrm{RCT}^{36}$ of donepezil for patients with progressive supranuclear palsy showed negative results. No favourable response to donepezil was seen in Huntington's Disease. ${ }^{37}$ Rivastigmine and donepezil have been used for Parkinson's associated dementia with promising but inconclusive results. ${ }^{38-40}$ In open-label studies, donepezil has been used for the treatment of cognitive impairment after traumatic brain injury with suggestive but inconclusive results. ${ }^{41,42} \mathrm{~A}$ few patients with $\mathrm{AD}$ associated with Down's syndrome have received treatment with donepezil with inconsistent outcomes. ${ }^{43,44}$ While a case report suggested benefit, ${ }^{45}$ a small study ${ }^{46}$ of donepezil in Wernicke-Korsakoff's syndrome did not show any therapeutic advantages.

\section{AdVERSE EFFECTS}

The Canadian product monographs of the ChEIs have detailed information on contraindications and precautions to their use. ${ }^{47-49}$ Gastrointestinal (GI) adverse effects (AEs) such as anorexia, nausea, vomiting, and diarrhea are the most common ones encountered. These AEs usually occur transiently when the ChEI is started or when the dose is increased, and are dose related. Tolerance to these AEs develop principally by increased AChE production. ${ }^{50}$ While central activation plays a role, ${ }^{50}$ they arise at least partially because of peripheral cholinergic effects as they can be prevented by the simultaneous administration of an antimuscarinic drug (glycopyrrolate) that does not penetrate the CNS. $^{4}$ The GI AEs appear to be more common with rivastigmine. For example, rivastigmine's product monograph states that $15 \%$ of those receiving 6-12 mg/day during the maintenance phase of their treatment had nausea. ${ }^{48}$ This compares to reported rates of $6 \%$ for donepezil $(10 \mathrm{mg} /$ day $)$ and $4-6 \%$ for galantamine (16-24 mg/day). ${ }^{47,49}$ One case of Boerhaave's syndrome (spontaneous rupture of the esophagus) from retching/vomiting has been reported with rivastigmine. ${ }^{51} \mathrm{~A}$ warning letter was sent out by Health Canada in 2001 advising 
physicians to re-titrate rivastigmine if treatment was interrupted by more than several days. Slower titration and administering rivastigmine with food appears to decrease the risk of GI side effects. Galantamine is also best taken with meals. If nausea and/or vomiting occur with rivastigmine or galantamine, first ensure that they are being taken with food, as this will decrease the Cmax and delay the Tmax of both agents. ${ }^{48,49}$ The area under the curve remains the same with galantamine ${ }^{49}$ and shows an increase with rivastigmine. ${ }^{48}$ If GI AEs occur, the dose of any of the ChEIs can be decreased with an option to retry the higher dose after four weeks if the lower dose is tolerated. While antiemetics can be used, we suggest trying the other measures first as a number of the anti-emetics (e.g., diphenhydramine, prochlorperazine) have anticholinergic properties that can lead to adverse cognitive effects. ${ }^{52,53}$ Weight loss has been seen with all three agents ${ }^{24,50}$ and is likely a class effect arising from GI AEs. It appears to occur more often in older female patients on higher doses of rivastigmine or galantamine. ${ }^{24,50,54}$ Weight should be monitored with nutritional support provided as needed.

Dizziness was frequently reported in the RCTs of the ChEIs. At the higher dose ranges, the rates of any occurrence of dizziness during the six-month trials ranged from $8 \%$ to $24 \%,{ }^{50}$ significantly more often than with placebo. ${ }^{12-14,46-49}$ In two of the more recent donepezil RCTs, dizziness was more common with active therapy. ${ }^{19,23}$ If disabling, dose reduction would be a reasonable initial approach.

Syncope, while uncommon (incidence of about $2 \%$ in the RCTs), occurred about twice as often in subjects receiving a ChEI than those on placebo. ${ }^{12,47,49}$ Possibly as a consequence of dizziness and syncope, accidental injuries and/or fractures were found to be nonsignificantly more frequent with active treatment in some studies. ${ }^{18,19,24,47}$ Like dizziness, syncope is a nonspecific symptom. The likely explanation is the vagotonic effect of ChEIs which could lead to a slowing of the heart rate or a heart block. Bradycardia appears to be a class effect but may be more common with donepezil. On average, there is approximately a two-to-three beats per minute slowing in the heart rate with donepezil. ${ }^{50}$ These agents should not be used by those with unexplained syncopal episodes. They should be used with caution, if at all, in those who have either a pre-existing bradycardia or a high degree AV block. Alzheimer's disease and other forms of dementia increase the risk of seizures. ${ }^{55}$ Cholinomimetics can lower seizure thresholds and seizures were seen in the RCTs of the ChEIs. A history of seizures requires a careful weighing of the relative benefits and risks of ChEI therapy, as would their occurrence during treatment.

As cholinomimetics, the ChEIs theoretically could induce urinary incontinence (UI). In the RCTs of these agents only a low rate (1-3\%) of UI with active treatment was reported - a frequency similar to those treated with placebo. However, a Japanese group reported that $7 \%$ of nearly one hundred patients treated with donepezil developed transient UI. ${ }^{56}$ Donepezil is associated with sleep disturbances, vivid dreams/nightmares, ${ }^{47,57}$ and hypnopompic hallucinations. ${ }^{58}$ While evening consumption of donepezil is still the standard recommendation, ${ }^{47}$ it should be taken in the morning by those with insomnia. Rivastigmine and galantamine are less likely to cause sleep disturbances. Donepezil has been associated with muscle cramps but not with significant weakness. ${ }^{50} \mathrm{~A}$ few case reports have been published showing a relationship between ChEI use and the Pisa syndrome (pleurothonus). ${ }^{59,60}$ While a theoretical possibility, the development or worsening of parkinsonism with ChEI treatment has not been definitely shown. Suggestive case reports can be found ${ }^{61-63}$ but despite specifically looking for parkinsonism, this was not found as an AE in two RCTs of high risk patients. ${ }^{23,29}$

The three available ChEIs are generally well-tolerated..$^{50,64}$ While reassuring, it must be emphasized that many serious AEs are only discovered after a drug has been in routine clinical use for years. ${ }^{65}$

\section{COMPARISON OF AVAILABLEAGENTS}

While all three available agents are inhibitors of AChE, there are pharmacological differences between them (see Table 1) which may be clinically relevant.

AChE inhibitors can be categorized as reversible, pseudoirreversible, and irreversible. ${ }^{66}$ Reversible inhibitors, like donepezil and galantamime, form weak ionic bonds with AChE. This typically means that frequent dosing is required but donepezil's long half-life obviates this concern. Rivastigmine is a pseudo-irreversible agent. It is hydrolyzed by cholinesterases but a carbamate moiety remains bound to the enzyme. This inhibits the activity of the enzyme for up to ten hours and leads to a longer duration of $\mathrm{AChE}$ inhibition for rivastigmine than would be predicted from its half-life (1-2 hours) ${ }^{67}$

Donepezil has a long duration of action and is given once daily while both rivastigmine and galantamine require twice daily dosing. Rivastigmine reaches the CNS more rapidly and has a quicker onset of pharmacological effect. This may explain the seemingly greater frequency of GI AEs seen with it. ${ }^{4,68}$ Acetylcholinesterase exists in various molecular forms $(\mathrm{G} 1, \mathrm{G} 2$, G4). In AD there is selective reduction of G4 while G1 remains unchanged. Rivastigmine has a significantly greater inhibitory effect on G1. Muscle cramps and weakness have not been reported with this agent possibly because G4 is the predominant form found at the neuromuscular junction. ${ }^{4}$

Since these drugs are ChEIs, interactions with drugs that have an effect on the cholinergic system can be expected. Concurrent use of a ChEI and an anticholinergic could result in pharmacological antagonism. A retrospective study found that $33 \%$ of older adults with probable dementia were taking anticholinergic drugs. ${ }^{69}$ In Saskatchewan, provincial reimbursement for a ChEI requires that patients not take anticholinergic medications with moderate to high activity. ${ }^{70}$ We agree with minimizing the use of anticholinergics in all patients treated with a ChEI. While the ChEIs could exaggerate the effects of succinylcholine-type muscle relaxants ${ }^{47-49}$ this has not been found to be a major problem in clinical practice as long as the anesthetist is informed of the use of the ChEI. Rivastigmine has a low likelihood of drug interactions because of its short half-life and relatively short duration of action, weak binding to plasma proteins (donepezil is $96 \%$ bound to plasma proteins, rivastigmine $40 \%$, galantamine 18\%), its breakdown while bound to AChE/BuChE, and its minimal metabolism by the P-450 system. A pharmacodynamic analysis of rivastigmine and a variety of other medications did not reveal any evidence of drug interactions. ${ }^{71}$

Both donepezil and galantamine are substrates for the P-450 enzymes CYP2D6 and CYP3A4. A variety of other medications are substrates, inhibitors, or inducers of these two enzymes. ${ }^{72}$ 
The maximum serum levels and area under the curve for donepezil did show modest increases with concurrent therapy with cimetidine (a nonspecific CYP inhibitor) and ketoconazole (a CYP 3A4 inhibitor). ${ }^{73}$ Co-administration with paroxetine (a CYP 2D6 inhibitor), ketoconazole, and erythromycin (a CYP 3A4 inhibitor) increased the bioavailability of galantamine. ${ }^{74} \mathrm{~A}$ possible clinically significant adverse drug interaction between donepezil and paroxetine has been reported..$^{75}$ While routine dose adjustments are not currently recommended, the prescribing physician should be aware of the potential for interactions.

Both rivastigmine and galantamine have additional modes of action. Of the three, only rivastigmine inhibits BuChE. In AD the CNS levels of $\mathrm{AChE}$ decrease while BuChE levels remain constant or increase. It is argued that rivastigmine will be more useful in the later stages of the disease as BuChEI develops greater functional importance. Butyrylcholinesterase may also have a role in disease progression. ${ }^{4,76} \mathrm{~A}$ recent study found a relationship between the inhibition of $\mathrm{BuChE}$ in cerebrospinal fluid (CSF) by rivastigmine and improved cognitive performance. ${ }^{5}$ It has been claimed that BuChE inhibition is responsible for the adverse peripheral cholinergic effects (e.g., GI symptoms) but this has not been proven. ${ }^{4}$ Galantamine is an allosterically potentiating ligand of nicotinic ACh receptors. By making the remaining nicotinic ACh receptors more sensitive to $\mathrm{ACh}$, a stronger response might ensue. Presynaptic stimulation could lead to the release of other neurotransmitters. Chronic lowlevel stimulation of nicotinic receptors might up-regulate their expression and possibly slow neurodegeneration. ${ }^{77,78}$ The actual clinical significance of these additional actions for the treatment of AD has not been shown.

Measurement of AChE in the cerebrospinal fluid of AD patients has shown increases after treatment with donepezil ${ }^{79,80}$ and galantamine. ${ }^{79}$ This increase was higher with donepezil, dose-dependent, and correlated with clinical response. ${ }^{79}$ In contrast, rivastigmine therapy was found to be associated with a lower level of AChE in the cerebrospinal fluid. ${ }^{80}$ This difference may be related to their differing mechanisms of AChEI. Rivastigmine is a pseudo-irreversible agent while both donepezil and galantamine are reversible inhibitors. ${ }^{79}$ Another suggested explanation is that prolonged donepezil and galantamine use, but not rivastigmine, leads to increased AChE synthesis and the development of tolerance. ${ }^{80}$ The clinical implications of these observations are uncertain.

A short-term (12 weeks), open-label AD study sponsored by the manufacturer of donepezil compared donepezil with rivastigmine.$^{81}$ The dose of rivastigmine was escalated rapidly, every two weeks. While comparable cognitive improvements were seen, GI AEs were more common with rivastigmine and, not surprisingly, both physician and caregiver satisfaction was higher with donepezil. This study can be criticized for its openlabel design, short duration, and the rapidity of the dose escalation schedule used for rivastigmine, which was more rapid than the titration schedule used for donepezil. Slower and more flexible titration schedules for rivastigmine have been reported to lead to lower rates of AEs. ${ }^{82}$

The same manufacturer sponsored an AD study comparing donepezil and galantamine which has been presented as a poster. ${ }^{83}$ In the 12 -week, multicentre, open-label study, donepezil treatment led to significantly greater improvements in cognition and function. Gastrointestinal AEs were more common with galantamine. The open-label design and short duration of this study limit any conclusions which can be reached.

\section{GUIDELINES FOR THE USE OF CHOLINESTERASE INHIBITORS}

There is growing agreement that ChEIs are a reasonable treatment option for AD. For example, the Canadian Consensus Conference on Dementia concluded that in the absence of contraindications a trial course of donepezil or rivastigmine can be prescribed to informed and willing patients with mild to moderate dementia due to $\mathrm{AD}^{84}$ (Note: When these recommendations were made, galantamine was not approved for use in Canada.) More recently the Quality Standards Subcommittee of the American Academy of Neurology published a practice parameter on the management of dementia. $^{85}$ One recommendation was that ChEIs should be considered in patients with mild to moderate AD.

If used, the next question is how. Lovestone et $\mathrm{al}^{86}$ published an early set of recommendations on the use of ChEIs. They suggested restricting use to those with a diagnosis of probable AD who have a Mini-Mental State Examination (MMSE) score between 10 and 24. After initiating treatment they suggested reviewing the patient after two weeks to inquire about side effects, and after three months to assess for evidence of efficacy. If treatment was continued, they recommended re-evaluating the patient's cognition and function every six months. At these reevaluations the patients' caregivers would be interviewed for their input. Favourable outcomes would include improvement, stabilization, or a slowing of the rate of decline. Treatment would be stopped if -

(1) the patient was nonadherent or intolerant of the ChEI;

(2) the patient continued to decline at the same rate as before initiating treatment; or,

(3) after a period of stability, accelerated decline occurred.

If the prescribing physician was uncertain about the benefit of continued treatment they suggested a six-week drug holiday with a re-evaluation.

More recent recommendations on how to use these agents are similar with one major modification (see Table 2) ${ }^{8,87}$ Data from donepezil studies suggest that interrupting therapy for prolonged periods of time (e.g., six weeks) can result in the loss of treatment benefits that cannot be recaptured. ${ }^{88}$ As uninterrupted therapy appears to achieve the best long-term outcomes, drug holidays are no longer recommended. An area of growing uncertainty is when to stop these agents because of disease progression. Formally physicians were advised to stop ChEIs once a patient progressed beyond a moderate stage. Sometimes this would be defined as dropping below a certain score on the MMSE (e.g., less than 10) or being institutionalized. An economic evaluation of donepezil for the treatment of $\mathrm{AD}$ in Canada assumed that the drug would be stopped once the patient's MMSE score dipped below $10 .{ }^{89}$ A recent study of donepezil targeted those with moderate to severe AD. ${ }^{23}$ Cognitive, global, functional, and/or behavioural benefits were seen. While the current indication in Canada is for mild to moderate $\mathrm{AD}$, decisions on when to terminate ChEI therapy will have to be individualized..$^{23,24}$

How ChEIs are actually used in everyday practice is unclear. 
Table 2: Recommendations for Initiating, Monitoring, and Discontinuation of ChEIs.

Establish treatment goals - improvement of symptoms; halt or slow rate of disease progression (cognition, function); prevention or improvement of behavioural manifestations; improvement in mood, contentedness and/or quality of life (patient or caregiver).

\section{Initiate therapy:}

1. Establish diagnosis of AD. Ensure stage is mild to moderate.

2. Baseline assessment of cognition (e.g., MMSE), function (e.g., interview caregiver), behaviour (e.g., interview caregiver), leisure activities (e.g., interview caregiver). Ensure no contraindications.

3. Explain treatment options; give realistic appraisal of likely benefit/side effects; obtain informed consent for treatment.

4. Initiate therapy; provide clear instructions to patient and caregiver. Instructions must be very clear on how to escalate dose.

\section{Monitoring:}

1. Re-evaluate patient in three months after starting (cognition, function, behaviour, leisure activities, presence of any adverse effects, global impression; obtain input from the caregiver).

2. With patient and caregiver, decide whether to carry on or stop.

3. If carry on, arrange to see every six months.

4. Patient and caregiver should be seen as required between the scheduled visits to deal with suspected adverse effects and intercurrent problems/concerns.

\section{Discontinue:}

1. Patient decides to stop/refuses to take; proxy decision-maker decides to stop.

2. The patient was nonadherent.

3. No response to therapy after reasonable trial (3-6 months).

4. Intolerable side effects.

5. Progression to stage where no benefit for patient from continued therapy.

A small American study using pharmacy claims data showed that the probability of a new user continuing to take donepezil was 0.797 at 90 days and 0.627 at 180 days. ${ }^{90}$ Among those still on donepezil at 180 days, $13.9 \%$ had continuous gaps in treatment of six weeks or longer.

The publicly funded drug benefit plans in certain Canadian provinces provide coverage for ChEIs. A common feature of all provinces which provide coverage is the requirement that a physician completes a form attesting that the patient does indeed have $\mathrm{AD}$ and scores within a defined range on the MMSE (e.g., 10 to 26). For continued reimbursement, the course of the illness must be monitored by the MMSE, an insensitive instrument for detecting the modest changes typically seen with ChEIs in the short term. Because of the inherent variability of the test, for a given individual a change of three or more points on the MMSE is required to be confident that a significant change has occurred. ${ }^{91,92}$ There is an argument for only looking for an impact on the MMSE score when sufficient time has elapsed to allow for detectable deterioration. In untreated AD the MMSE drops on average 3.3 points per year, although the rate of decline is typically not linear and shows a good deal of variability. ${ }^{93}$ Finding no change or an improvement on the MMSE after oneyear of ChEI treatment would suggest a benefit.

The clinician should not rely solely on the MMSE to assess whether a patient has responded. It is vital to assess functional status and behaviour as well as cognition. It is necessary to interview a person who has regular, on-going contact with the patient in order to obtain their perspective. The ChEIs can delay the rate of decline or loss of functional abilities. They may also help prevent or treat the dysfunctional behaviours seen with AD.

Cholinesterase inhibitors will often be used in combination with agents like vitamin $\mathrm{E}$ and Ginkgo biloba. ${ }^{94}$ There are no clinical data to support or discourage this practice. As a general rule combination therapy makes most sense if the agents are felt to have different mechanisms of action. Combination therapy for AD will likely become even more commonly studied and used in the future.

\section{SELECTION OF WHICH AGENT?}

We view donepezil, rivastigmine, and galantamine as a single drug class because of their similar mechanism of action cholinesterase inhibition. ${ }^{95}$ When comparing their efficacy there is no high quality level 1 evidence (i.e., from head-to-head RCT) on which to base our conclusions. Level 2 evidence (i.e., across RCTs of the different drugs versus placebo) does not, in our opinion, favour one drug over another. Level 4 evidence (i.e., between nonrandomized studies) would at best be viewed as hypothesis generating. In clinical practice, the selection of which ChEI to use will be based on considerations such as $\mathrm{AE}$ profiles/patient tolerance, ease of administration (i.e., dosing frequency), familiarity/clinical experience with the various agents, and beliefs about the importance of the noted differences between the agents. As the price per day of treatment is nearly equivalent, cost is generally a neutral factor. The cost of a 30-day supply (including dispensing fee) is $\$ 147.78$ to $\$ 159.89$ for donezepil (Calgary Health Region, Pharmacy Services). Rivastigmine and galantamine cost approximately $\$ 5$ to $\$ 10$ more per month.

\section{SWITCHING RECOMMENDATIONS}

Reasons for switching from one ChEI to another include (1) no response to the first agent;

(2) intolerable side effects from the current ChEI; and,

(3) at the request of the patient and/or caregiver, often in the hope of additional benefit.

This can be done relatively easily. A simple protocol for switching to galantamine from either donepezil or rivastigmine has been published. ${ }^{96}$ With this protocol, no wash-out period is required if the switch is being made at the patient's request or because of nonresponse. (If the switch is being made because of intolerable side effects, it is recommended that there be a washout of up to seven days or until the symptoms resolve.) The new agent is started the day after stopping the first agent. Standard starting doses with typical subsequent escalation schedules are then used. Monitoring for efficacy and side effects would then take place as with any ChEI. For switching from donepezil to 
rivastigmine, a one-week protocol with overlap/dual administration of both agents has been studied. ${ }^{97}$ This was found to be effective though complex. Another switching protocol where donepezil was tapered and discontinued before the patient started low-doses of rivastigmine was associated with cognitive decline in some patients. ${ }^{98}$ We do not recommend this latter regimen.

In the short term, switching from a full therapeutic dose of one ChEI to either a subtherapeutic dose or one that is minimally effective of another agent may cause worsening of the cognitive, functional, and/or behavioural manifestations of the illness during the changeover. Even when full therapeutic doses are reached, the consequences of switching for an individual patient are unknown - they may do better, the same, or worse on the new agent. There was an open-label, prospective, multicentre, sixmonth study sponsored by the manufacturer of rivastigmine on the consequences of switching to rivastigmine from donepezil. ${ }^{99}$ Before the changeover, most $(79.6 \%)$ of the 382 subjects had either experienced a two-point or greater decrease in their MMSE score or a loss of functional autonomy while on donepezil. On the global measure used in the study $26.1 \%$ of subjects showed an improvement, $30.1 \%$ no change, and $43.9 \%$ a deterioration at the end of the six months of rivastigmine therapy. The mean change on the MMSE for all subjects was -0.7 points. Most subjects either showed no change $(41.6 \%)$ or a deterioration (43\%) in their ability to perform instrumental activities of daily living. Most subjects $(91.4 \%)$ achieved a dose of at least $6 \mathrm{mg} /$ day of rivastigmine. Most (84.6\%) of those who could not tolerate donepezil were able to take rivastigmine for the study duration. As there was no comparison group, we cannot say if these results were better or worse than expected. While this study shows that changing from donepezil to rivastigmine is possible, it does not, in our opinion, offer a strong argument for or against switching from one ChEI to another.

Currently there are no published peer-reviewed data to support using a combination of ChEIs.

\section{CONCLUSION}

Cholinesterase inhibitors have been an important advance in the pharmacotherapy of $\mathrm{AD}$. We believe they should be prescribed for consenting individuals with a mild to moderate dementia where Alzheimer pathology is felt to be a contributing factor and there is no contraindication. This would include DLB (where Alzheimer pathology is commonly found) ${ }^{100}$ and mixed dementias (where Alzheimer pathology is felt to be present) as well as cases of probable AD. Existing data indicate that the three available agents have similar efficacy. Pending the results of high quality head-to-head RCTs the choice of which agent to use will be based on secondary characteristics. ${ }^{8,84}$ Monitoring therapy requires a commitment to perform periodic comprehensive assessments. Current trials are exploring the use of ChEIs in mild cognitive impairment, moderate-to-severe $\mathrm{AD}$, and other forms of dementia. Until more effective agents become available, ChEIs will remain the standard pharmacotherapy for $\mathrm{AD}$.

\section{REFERENCES}

1. Canadian Study of Health and Aging Working Group. Canadian Study of Health and Aging: study methods and prevalence of dementia. CMAJ 1994; 150:899-913.

2. The Canadian Study of Health and Aging Working Group. The incidence of dementia in Canada. Neurology 2000; 55:66-73.

3. Cummings JL. Cholinesterase inhibitors: a new class of psychotropic compounds. Am J Psychiatry 2000; 157:4-15.

4. Weinstock M. Selectivity of cholinesterase inhibitors - clinical implications for the treatment of Alzheimer's disease. CNS Drugs 1999; 12:307-323.

5. Giacobini E, Spiegel R, Enz A, Veroff AE, Cutler NR. Inhibition of acetyl- and butyryl-cholinesterase in the cerebrospinal fluid of patients with Alzheimer's disease by rivastigmine: correlation with cognitive benefit. J Neural Transm 2002; 109: 1053-1065.

6. Darvesh S, Granthan DL, Hopkins DA. Distribution of butyrylcholinesterase in the human amydala and hippocampal formation. J Comp Neurol 1998; 393:374-390.

7. Bartus RT, Dean III RL, Beer B, Lippa AS. The cholinergic hypothesis of geriatric memory dysfunction. Science 1982; 217:408-417.

8. Gauthier S. Advances in pharmacotherapy of Alzheimer's disease. CMAJ 2002; 166(5):616-623.

9. Giacobini E. Is anti-cholinesterase therapy of Alzheimer's disease delaying progression? Aging Clin Exp Res 2001; 13:247-254.

10. Davis KL, Mohs RC, Marin D, et al. Cholinergic markers in elderly patients with early signs of Alzheimer disease. JAMA 1999; 281:1401-1406.

11. DeKosky ST, Ikonomovic MD, Styren SD, et al. Upregulation of choline acetyltransferase activity in hippocampus and frontal cortex of elderly subjects with mild cognitive impairment. Ann Neurol 2002; 51:145-155.

12. Birks JS, Melzer D, Beppu H. Donepezil for mild and moderate Alzheimer's disease. Cochrane Database of Systematic Reviews, Issue 2, 2001:1-40.

13. Birks J, Grimley Evans J, Iakovidou V,Tsolaki M. Rivastigmine for Alzheimer's disease. Cochrane Database of Systematic Reviews, Issue 2, 2001:1-58.

14. Olin J, Schneider L. Galantamine for Alzheimer's disease. Cochrane Database of Systematic Reviews, Issue 2, 2001:1-36.

15. Anand R, Messina J, Hartman R. Dose-response effect of rivastigmine in the treatment of Alzheimer's disease. Int J Geriatr Psychopharmacol 2000; 2:68-72.

16. Raskind MA, Peskind ER, Wessel T, Yuan W and the Galantamine USA-1 Study Group. Galantamine in AD - a 6-month randomized, placebo-controlled trial with a 6-month extension. Neurology 2000; 54:2261-2268.

17. Wolfson C, Moride Y, Perrault A, et al. Drug treatments for Alzheimer's disease. I. A comparative analysis of clinical trials. Ottawa, Ontario: Canadian Coordinating Office for Health Technology Assessment (CCOTHA); 2000 May.

18. Mohs RC, Doody RS, Morris JC, Ieni JR, et al. A 1-year, placebocontrolled preservation of function survival study of donepezil in AD patients. Neurology 2001; 57:481-488.

19. Winblad B, Engedal K, Soininen H, et al. A 1-year, randomized placebo-controlled study of donepezil in patients with mild to moderate AD. Neurology 2001; 57:489-495.

20. Rogers SL, Doody RS, Pratt RD, Ieni JR. Long-term efficacy and safety of donepezil in the treatment of Alzheimer's disease: final analysis of a US multicenter open-label study. Euro Neuropsychopharma 2000; 10:195-203.

21. Farlow M, Anand R, Messina J, Hartman R, Veach J. A 52-week study of the efficacy of rivastigmine in patients with mild to moderately severe Alzheimer's disease. Eur Neurol 2000; 44:236-241.

22. Raskind MA, Peskind ER, Wessel T, et al. Galantamine in AD: a 6month randomized, placebo-controlled trial with a 6-month extension. Neurology 2000; 54:2261-2268.

23. Feldman H, Gauthier S, Hecker J, et al. A 24-week, randomized, double-blind study of donepezil in moderate to severe Alzheimer's disease. Neurology 2001; 57:613-620

24. Tariot PN, Cummings JL, Katz IR, et al. A randomized, doubleblind, placebo-controlled study of the efficacy and safety of donepezil in patients with Alzheimer's disease in the nursing home setting. J Am Geriatr Soc 2001; 49:1590-1599.

25. Anonymous. Donepezil (Aricept) for Alzheimer's disease. Med Lett Drugs Ther 1997; 39(1002):54. 
26. Anonymous. Rivastigmine (Exelon) for Alzheimer's disease. Med Lett Drugs Ther 2000; 42(1089):93-94.

27. Anonymous. Galantamine (Reminyl) for Alzheimer's disease. Med Lett Drugs Ther 2001; 43(1107):53-54.

28. Knopman DS. An overview of common non-Alzheimer dementias. Clin Geriatr Med 2001; 17:281-301.

29. McKeith I, Del Ser T, Spano P, et al. Efficacy of rivastigmine in dementia with Lewy bodies: a randomised, double-blind, placebo-controlled international trial. Lancet 2000;356:20312036.

30. Shea C, MacKnight C, Rockwood K. Donepezil for treatment of dementia with Lewy bodies: a case series of nine patients. Int Psychogeriatr 1998; 10:229-238.

31. Samuel W, Caligiuri M, Galasko D, et al. Better cognitive and psychopathologic response to donepezil in patients prospectively diagnosed as dementia with Lewy bodies: a preliminary study. Int J Geriatr Psychiatry 2000; 15:794-802.

32. Erkinjuritti T, Kurz A, Gauthier S, et al. Efficacy of galantamine in probable vascular dementia and Alzheimer's disease combined with cerebrovascular disease: a randomized trial. Lancet 2002; 359:1283-1290.

33. Moretti R, Torre P, Antonello RM, Cazzato G. Rivastigmine in subcortical vascular dementia: a comparison trial on efficacy and tolerability for 12 months follow-up. Eur J Neurol 2001; 8:361362.

34. Mendez MF, Younesi FL, Perryman KM. Use of donepezil for vascular dementia: preliminary clinical experience. J Neuropsychiatry Clin Neurosci 1999; 11:268-270.

35. Fabbrini G, Barbanti P, Bonifati V, et al. Donepezil in the treatment of progressive supranuclear palsy. Acta Neurol Scand 2001; 103:123-125.

36. Litvan I, Phipps M, Pharr VL, et al. Randomized placebo-controlled trial of donepezil in patients with progressive supranuclear palsy. Neurology 2001; 57:467-473.

37. Fernandez HH, Friedman JH, Grace J, Beason-Hazen S. Donepezil for Huntington's disease. Mov Disord 2000;15:173-176.

38. Reading PJ, Luce AK, McKeith IG. Rivastigmine in the treatment of parkinsonian psychosis and cognitive impairment: preliminary findings from an open trial. Mov Disord 2001; 16:1171-1174

39. Korczyn AD. Dementia in Parkinson's disease. J Neurol 2001; 248 (Suppl 3):III1-4.

40. Werber EA, Rabey JM. The beneficial effect of cholinesterase inhibitors on patients suffering from Parkinsons's disease and dementia. J Neural Transm 2001; 108:1319-1325.

41. Whelan FJ, Walker MS, Schultz SK. Donepezil in the treatment of cognitive dysfunction associated with traumatic brain injury. Ann Clin Psychiatry 2000; 12:131-135.

42. Masanic CA, Bayley MT, VanReekum R, Simard M. Open-label study of donepezil in traumatic brain injury. Arch Phys Med Rehabil 2001; 82:896-901.

43. Hemingway-Eltomey JM, Lerner AJ. Adverse effects of donepezil in treating Alzheimer's disease associated with Down's syndrome. Am J Psychiatry 1999; 156:1470.

44. Kishnani PS, Spiridigliozzi GA, Heller JH, et al. Donepezil for Down's syndrome. Am J Psychiatry 2001; 158:143.

45. Iga J-I, Araki M, Ishimoto Y, Ohmori T. A case of Korsakoff's syndrome improved by high doses of donepezil. Alcohol Alcohol 2001;36:553-555.

46. Sahin HA, Gurvit IH, Bilgic B, Hanagasi HA, Emre M. Therapeutic effects of an acetylcholinesterase inhibitor (donepezil) on memory in Wernicke-Korsakoff's disease. Clin Neuropharmacol 2002; 25:16-20.

47. Anonymous. Aricept (Product Monograph). In: 2002 Compendium of Pharmaceuticals and Specialties - The Canadian Drug Reference for Health Professionals. Canadian Pharmacists Association (Ottawa), 2002;161-163.

48. Anonymous. Exelon (Product Monograph). In: 2002 Compendium of Pharmaceuticals and Specialties - The Canadian Drug Reference for Health Professionals. Canadian Pharmacists Association (Ottawa), 2002;612-615.

49. Anonymous. Reminyl (Product Monograph). 2002 Compendium of Pharmaceuticals and Specialties - The Canadian Drug Reference for Health Professionals. Canadian Pharmacists Association (Ottawa), 2002;1445-1449.

50. Gauthier S. Cholinergic adverse effects of cholinesterase inhibitors in Alzheimer's disease, epidemiology and management. Drugs Aging 2001; 18:853-862.

51. Babic T, Banfic L, Papa J, et al. Spontaneous rupture of oesophagus (Boerhaave's syndrome) related to rivastigmine. Age Ageing 2000; 29:370-371

52. Anonymous. Some drugs that cause psychiatric symptoms. Med Lett Drugs Ther 1998; 40(1020):21-24.

53. Agostini JV, Leo-Summers L, Inouye SK. Cognitive and other adverse effects of Diphenhydramine use in hospitalized older patients. Arch Intern Med 2001; 161:2091-2097.

54. Spencer CM, Noble J. Rivastigmine - a review of its use in Alzheimer's disease. Drug Aging 1998; 13:391-411.

55. Hesdorffer DC, Hauser WA, Annegers JF, Kokmen E, Rocca WA. Dementia and adult-onset unprovoked seizures. Neurology 1996; 46:727-730.

56. Hashimoto M, Imamura T, Tanimukai S, Kazui H, Mori E. Urinary incontinence: an unrecognized adverse effect with donepezil. Lancet 2000; 356:568.

57. Ross JS, Shia-Hain JR. Aricept-induced nightmares in Alzheimer's disease: 2 case reports. J Am Geriatr Soc 1998; 46:119-120.

58. Yorston GA, Gray R. Hypnopompic hallucinations with donepezil. J Psychopharmacol 2000; 14:303-304.

59. Kwok YT, Han IW, Baik J, Koo MS. Relation between cholinesterase inhibitor and Pisa syndrome. Lancet 2000; 355:2222.

60. Miyaoka T, Seno H, Yamamori C, et al. Pisa syndrome due to a cholinesterase inhibitor (donepezil): a case report. J Clin Psychiatry 2001; 62:573-574.

61. Bourke D, Druckenbrod RW. Possible association between donepezil and worsening of Parkinson's disease. Ann Pharmacother 1998; 32:610-611.

62. Magnuson TM, Keller BK, Burke WJ. Extrapyramidal side effects in a patient treated with risperidone plus donepezil. Am J Psychiatry 1998; 155:1458-1459.

63. Arai M. Parkinsonism onset in a patient concurrently using tiapride and donepezil. Int Med 2000; 39:863.

64. Springuel P. Donepezil: suspected adverse reactions. Canadian Adverse Drug Reaction Newsletter 1998; 8(3):2-3.

65. Lasser KE, Allen PD, Woolhandler SJ, et al. Timing of new black box warnings and withdrawals for prescription medications. JAMA2002; 287:2215-2220.

66. Farlow MR, Hake AM. Mechanism of action and metabolism of acetylcholinesterase inhibitors: implications for treatment. Int $\mathbf{J}$ Geriatr Pschopharmacology 1998; 1 (Suppl 1):S2-S6.

67. Polinsky RJ. Clinical pharmacology of rivastigmine: a newgeneration acetylcholinesterase inhibitor for the treatment of Alzheimer's disease. Clin Ther 1998; 20:634-647.

68. Imbimbo BP. Pharmacodynamic-tolerability relationships of cholinesterase inhibitors for Alzheimer's disease. CNS Drugs 2001; 15:375-390

69. Roe CM, Anderson MJ, Spivack B. Use of anticholinergic medications by older adults with dementia. J Am Geriatr Soc 2002; 50:836-842.

70. Anonymous. Reference list of drugs with anticholinergic effects. Aricept/Exelon Exception Drug States Application. Saskatchewan Health, 2001.

71. Grossberg GT, Stahelin HB, Messina JC, Anand R, Veach J. Lack of adverse pharmacodynamic drug interactions with rivastigmine and twenty-two classes of medications. Int J Geriatr Psychiatry 2000; 15:242-247.

72. Anonymous. Drug interactions. Med Lett Drugs Ther 1991; 41 (1056): 61-62.

73. Tisco PJ, Rogers SL, Perdomo CA, Friedhoff LT. The effect of cimetidine and ketoconazole on the pharmacokinetics of donepezil. Clin Pharmacol Ther 1998; 63:234.

74. Scott LJ, Goa KL. Galantamine - a review of its use in Alzheimer's disease. Drugs 2000; 60:1095-1112.

75. Carrier L. Donepezil and paroxetine: possible drug interaction. J Am Geriatr Soc 1999; 47:1037. 
76. Ballard CG. Advances in the treatment of Alzheimer's disease: benefits of dual cholinesterase inhibition. Eur Neurol 2002; 47:64-70.

77. Samochocki M, Zerlin M, Jostock R, et al. Galantamine is an allosterically potentiating ligand of the human alpha4/beta2 nAChR. Acta Neurol Scand 2000; Suppl 176:68-73.

78. Maelicke A, Samochocki M, Jostock R, et al. Allosteric sensitization of nicotinic receptors by galantamine, a new treatment strategy for Alzheimer's disease. Biol Psychiatry 2001; 49:279-288.

79. Davidson P, Blennow K, Andreasen N, et al. Differential increase in cerebrospinal fluid-acetylcholinesterase after treatment with acetycholinesterase inhibitors in patients with Alzheimer's disease. Neurosci Lett 2001; 300:157-160.

80. Amici S, Lanari A, Romani R, et al. Cerebrospinal fluid acetylcholinesterase activity after long-term treatment with donepezil and rivastigmine. Mech Age Dev 2001; 122:20572062.

81. Wilkinson D, Passmore P, Bullock R, et al A multinational, randomised, 12-week, comparative study of donezepil and rivastigmine in patients with mild to moderate Alzheimer's disease. Int J Clin Prac 2002;56:441-446.

82. Shua-Haim JR, Smith JM, Amin S. Safety and tolerability of slow titration of rivastigmine (Exelon) in the treatment of patients with Alzheimer's disease (AD): an overall analysis of two prospective studies. J Am Geriatr Soc 2001; 49(4):S76-S77.

83. Jones RW, Passmore P, Wetterberg P, et al. First head to head study comparing tolerability and efficacy of donepezil and galantamine in Alzheimer's disease. 7th International Geneva Springfield Symposium on Advances in Alzheimer Therapy, Geneva, April 36, 2002; poster.

84. Patterson C, Gauthier S, Bergman $\mathrm{H}$, et al. The recognition, assessment and management of dementing disorders: conclusions from the Canadian Consensus Conference on Dementia. Can J Neurol Sci 2001; 28 (Suppl 1): S3-S16.

85. Doody RS, Stevens JC, Beck C, et al. Practice parameter: management of dementia (an evidence-based review). Neurology 2001; 56:1154-1156.

86. Lovestone S, Graham N, Howard R. Guidelines on drug treatments for Alzheimer's disease. Lancet 1997; 350:233.

87. Patterson C, Cohen C, Hogan DB. Dementia. In: Compendium of Pharmaceuticals and Specialties 2002 (Carol Repchinsky, editorin-chief). Canadian Pharmacists Association (Ottawa), 2002; L56-L58.

88. Doody RS, Geldmacher DS, Gordon B, Perdomo CA, Pratt RD.
Open-label, multicentre, phase 3 extension study of the safety and efficacy of donepezil in patients with Alzheimers disease. Arch Neurol 2001; 58:427-433.

89. O'Brien BJ, Goeree R, Hux M, et al. Economic evaluation of donepezil for the treatment of Alzheimer's disease in Canada. J Am Geriatr Soc 1999; 47:570-578.

90. Roe CM, Anderson MJ, Spivack B. How many patients complete an adequate trial of donepezil? Alz Dis Assoc Disord 2002; 16:4951.

91. Bowie P, Branton T, Holmes J. Should the Mini Mental State Examination be used to monitor dementia treatments? Lancet 1999; 354:1527-1528.

92. Sands LP, Katz I, Schneider L. Assessing individual patients for cognitive benefits from acetylcholinesterase inhibitors. Alz Dis Assoc Disord 1999; 13:26-33.

93. Han L, Cole M, Bellavance F, McCusker J, Primeau F. Tracking cognitive decline in Alzheimer's disease using the MMSE: a meta-analysis. Int Psychogeriatr 2000; 12:231-247.

94. Doraiswamy PM, Steffens DC. Combination therapy for early Alzheimer's disease: what are we waiting for? J Am Geriatr Soc 1998; 46:1322-1324.

95. McAlister FA, Laupacis A, Wells GA, Sackett DL. Users'guide to the medical literature, XIX. Applying clinical trial results. B. Guidelines for determining whether a drug is exerting (more than) a class effect. JAMA1999; 282:1371-1377.

96. Morris JC (Ed.). Therapeutic continuity in Alzheimer's disease: switching patients to galantamine. Clin Ther 2001; 23 (Supplement A):A1-A40.

97. Shua-Haim JR, Smith JM, Amin S. Results of one-week overlapcrossover study of donepezil (Aricept) to rivastigmine (Exelon) in Alzheimer's disease patients: a one-month prospective study. J Am Geriatr Soc 2001; 49(4):S76.

98. Shua-Haim JR, Smith JM, Amin S. Crossover results of donepezil (Aricept) to rivastigmine (Exelon) in Alzheimer's disease patients: a two-month prospective study. J Am Geriatr Soc 2001; 49(4):S76.

99. Auriacombe S, Pere J-J, Loria-Kanza Y, Vellas B. Efficacy and safety of rivastigmine in patients with Alzheimer's disease who failed to benefit from treatment with donepezil. Curr Med Res Opin 2002; 18(3):129-138.

100. Report of the Consortium on DLB International Workshop. Consensus guidelines for the clinical and pathologic diagnosis of dementia with Lewy bodies (DLB). Neurology 1996; 47:11131124 